\title{
A single nucleotide polymorphism in the human PIGK gene associates with low PIGK expression in colorectal cancer patients
}

\author{
SANTANU DASGUPTA ${ }^{1}$, PRODIPTO PAL ${ }^{2}$, NITAI D. MUKHOPADHYAY ${ }^{3}$, YUMEI FU ${ }^{2}$, \\ EDWARD A. RATOVITSKI ${ }^{2}$, CHUL-SO MOON ${ }^{2}$, MOHAMMAD OBAIDUL HOQUE ${ }^{2}$, \\ PAUL B. FISHER ${ }^{1}$ and BARRY TRINK ${ }^{2}$
}

\author{
${ }^{1}$ Department of Human and Molecular Genetics, VCU Institute of Molecular Medicine, VCU Massey Cancer Center, \\ Virginia Commonwealth University, School of Medicine, Richmond, VA 23298; ${ }^{2}$ Department of Otolaryngology, \\ Johns Hopkins University, Baltimore, MD 21231; ${ }^{3}$ Department of Biostatistics, \\ Virginia Commonwealth University, Richmond, VA 23298, USA
}

Received April 5, 2012; Accepted May 21, 2012

DOI: 10.3892/ijo.2012.1567

\begin{abstract}
Colorectal cancer (CRC) represents one of the highest incidences of cancers worldwide. Phosphatidylinositol glycan, class K (PIGK), is a crucial member of the glycosylphosphatidylinositol transamidase (GPIT) protein complex that attaches a diverse group of macromolecules to the plasma membrane of eukaryotes. However, the precise role of PIGK in tumorigenesis remains largely unknown. Recently, we reported low expression of PIGK protein in primary tumors compared to paired normal tissues of colorectal cancer (CRC) patients. To understand the mechanism underlying this phenomenon, we performed sequencing of all 10 exons of the PIGK gene in 45 CRC patients. Corresponding PIGK protein expression was also evaluated in these patients by immunohistochemistry. No mutation was detected in the coding regions, however, we found a single nucleotide polymorphism $(\mathrm{C} / \mathrm{C} \rightarrow \mathrm{C} / \mathrm{G}$ or $\mathrm{G} / \mathrm{G}$; rs1048575) in the $3^{\prime} \mathrm{UTR}$ of the PIGK gene in 67\% (30/45) of the patients. Most of the patients $(22 / 26,85 \%)$ with the altered alleles were of Jewish origin. In comparison, 47\% (8/17) of the Arabian patients exhibited the altered $\mathrm{C} / \mathrm{G}$ alleles. We observed a significantly low $(\mathrm{p}<0.002)$ expression of PIGK protein in the patients with the altered alleles ( $/ \mathrm{G}$ or $\mathrm{G} / \mathrm{G})$ compared to the ancestral alleles $(\mathrm{C} / \mathrm{C})$. Similarly to the $\mathrm{CRC}$ patients, we also examined 5 HCC patients and two HCC cell lines (Hep3B and
\end{abstract}

Correspondence to: Dr Santanu Dasgupta, Department of Human and Molecular Genetics, Virginia Commonwealth University, School of Medicine, 1220 E Broad St., Richmond, VA 23298, USA E-mail: sdasgupta@vcu.edu

Dr Barry Trink, Department of Otolaryngology, Johns Hopkins University, 1550 Orleans St., Baltimore, MD 21231, USA

E-mail: btrink@jhmi.edu

Key words: colorectal cancer, PIGK, 3'UTR, single nucleotide polymorphism
HepG2) for PIGK genotype (SNP-1048575) and corresponding protein expression. We observed altered alleles $(\mathrm{C} / \mathrm{G}$ or $\mathrm{G} / \mathrm{G})$ and corresponding low PIGK protein expression in 4 out of $5(80 \%)$ primary HCC tumors. Among the HCC cell lines, HepG2 line exhibited ancestral $\mathrm{C} / \mathrm{C}$ alleles, whereas Hep3B showed altered $\mathrm{C} / \mathrm{G}$ alleles. Similar to the HCC patients, Hep3B line with the altered alleles $(\mathrm{C} / \mathrm{G})$ exhibited significantly low (Student's t-test, $\mathrm{p}<0.002)$ PIGK protein expression compared to the Hep3B line carrying the ancestral $(\mathrm{C} / \mathrm{C})$ alleles. To examine the exogenous PIGK protein expression status, we transiently transfected both HepG2 (C/C alleles) and Hep3B (C/G alleles) cell lines with wt-PIGK constructs. We detected exogenously expressed PIGK protein in HepG2 $(\mathrm{C} / \mathrm{C})$ cells, but no PIGK expression was detectable in Hep3B $(\mathrm{C} / \mathrm{G})$ cells at either mRNA or protein level. Our results demonstrate, for the first time, a link between the SNP 1048575 and low PIGK expression in CRC/HCC patients and also suggest a possible association between altered PIGK expression and disease susceptibility.

\section{Introduction}

Colorectal cancer (CRC) is one of the highest incidence cancers worldwide (1). In the US, CRC is the fourth most common cancer in men and women (1) and approximately 3,000 new cases are diagnosed annually both in the Jewish male and female population (2-4). It is uncommon in the non-Jewish (Arab) population. This is attributed to different genetic susceptibility and/or lifestyle and diet (2-4). Gene mutation or genetic variations, whether it is at the single nucleotide polymorphism (SNP) or structural level, could also contribute to the development of CRC as shown in a number of Genome Wide Association (GWAS) and related studies (5-9). The glycosylphosphatidylinositol transamidase (GPIT) complex is a family of proteins that assists in attaching a diverse group of macromolecules to the plasma membrane of eukaryotes (10). The GPIT complex is composed of 5 subunits namely PIGU, PIGT, GPAA1, PIGS and PIGK (10). Among these 5 subunits, PIGK (GPI8) plays a crucial role in protein-GPI anchoring $(10,11)$. It is well established that PIGK catalyzes the endoproteolysis and amidation steps involved in 
transfer of GPI to proteins (10). However, the role of PIGK in tumorigenesis remains largely unknown. Recently, we reported a low expression of PIGK protein in some CRC, hepatocellular (HCC) and urothelial cell carcinoma (UCC) patients (11). We hypothesize that the altered expression of PIGK could be due to mutation in the coding regions of this gene. As a pilot study, we examined all 10 exons of the PIGK gene in 45 CRC patients by direct sequencing. Immunohistochemistry was performed on the same $45 \mathrm{CRC}$ patients to examine corresponding protein expression. We did not detect any mutation in the exons, but a $\mathrm{SNP}(\mathrm{C} / \mathrm{C} \rightarrow \mathrm{C} / \mathrm{G}$ or $\mathrm{G} / \mathrm{G}$; rs1048575) was found in the 3'UTR immediately after the stop codon of the PIGK gene in $67 \%$ $(30 / 45)$ of the samples. We also observed a significantly low $(\mathrm{P}<0.002)$ expression of PIGK protein in all patients with the altered alleles $(\mathrm{C} / \mathrm{G}$ or $\mathrm{G} / \mathrm{G})$ compared to the ancestral alleles $(\mathrm{C} / \mathrm{C})$. Similar observations were made on PIGK expression in a several transformed human colon cell lines with the ancestral $(\mathrm{C} / \mathrm{C})$ and altered $(\mathrm{C} / \mathrm{G})$ genotype. These results suggest an association between SNP-1048575 and low PIGK expression in CRC patients.

\section{Materials and methods}

Patient history and tissue samples. Matched adjacent normal and tumor tissues from $45 \mathrm{CRC}$ patients and the HCC samples were collected at the Johns Hopkins University (JHU) as per IRB approved protocol. Formalin-fixed paraffin-embedded (FFPE) tumor tissue sections $(5 \mu \mathrm{m})$ were procured from all $45 \mathrm{CRC}$ patients for immunohistochemical (IHC) analysis. All the subsequent analysis of tissue samples, IHC staining was performed at JHU. Detailed patient information is shown in Table I.

Cell lines. We obtained 2 human non-tumorigenic colonic cell lines; CCD841 and FHC and two hepatocellular carcinoma (HCC) lines H2pG2 and Hep3B from ATCC. All cell lines were cultured in ATCC recommended medium. The cell lines were periodically chacked for mycoplasma contamination using Mycoplasma Detection kit from Sigma (MP-0025). The tissue culture media and reagents were purchased either from ATCC or Invitrogen.

DNA extraction and PIGK exon sequencing. Genomic DNA was extracted from the microdissected tumor and normal tissue samples and cell lines as described (12). The list of primers is given in Table II. The PCR was carried out in a $50 \mu \mathrm{l}$ reaction volume with the conditions as follows: $95^{\circ} \mathrm{C}$ for $5 \mathrm{~min}, 1$ cycle; $94^{\circ} \mathrm{C}$ for $30 \mathrm{sec}, 55^{\circ} \mathrm{C}$ for $30 \mathrm{sec}, 72^{\circ} \mathrm{C}$ for $7 \mathrm{~min}, 40 \mathrm{cycles}$; and final extension at $72^{\circ} \mathrm{C}$ for $10 \mathrm{~min}$. All amplified products were analyzed on $1 \%$ agarose gels, cut, purified and sequenced using the ABI Big Dye Cycle Sequencing kit (Applied Biosystems). All experiments were carried out at JHU.

Genotyping assay for SNP rs 1048575. TaqMan ${ }^{\mathrm{TM}}$ (Fluorogenic 5' nuclease) assay was used for typing our candidate SNP (rs1048575). The forward and reverse primers and respective allele-specific probes were obtained from Applied Biosystems (Applied Biosystems). PCR was conducted in ABI 9700 thermocycler, and the end-point results were auto-scored using the ABI 7900HT Sequence Detection System (SDS; version 2.3). To ensure reliability of genotyping data, each of the samples
Table I. Colorectal cancer patients with the PIGK genotype and corresponding PIGK protein expression.

\begin{tabular}{|c|c|c|c|}
\hline Patient ID & Genotype & Stage & $\begin{array}{c}\text { PIGK } \\
\text { expression }^{\mathrm{a}}\end{array}$ \\
\hline C592 & $\mathrm{CC}$ & IV & +++ \\
\hline C127 & $\mathrm{CC}$ & IV & +++ \\
\hline C758 & $\mathrm{CC}$ & I & +++ \\
\hline C358 & $\mathrm{CC}$ & IIA & +++ \\
\hline C155 & $\mathrm{CC}$ & IIA & +++ \\
\hline $\mathrm{C} 277$ & $\mathrm{CC}$ & I & +++ \\
\hline C193 & $\mathrm{CC}$ & IIB & +++ \\
\hline C410 & $\mathbf{C} / \mathbf{G}$ & IIIB & + \\
\hline C307 & $\mathrm{C} / \mathrm{G}$ & IIIB & ++ \\
\hline C183 & $\mathrm{C} / \mathrm{G}$ & III & ++ \\
\hline C301 & $\mathrm{C} / \mathrm{G}$ & IIA & + \\
\hline C345 & $\mathrm{C} / \mathrm{G}$ & IIIC & + \\
\hline C374 & $\mathbf{C} / \mathbf{G}$ & IIIA & + \\
\hline C330 & $\mathrm{C} / \mathrm{G}$ & IIA & + \\
\hline C217 & $\mathbf{C} / \mathbf{G}$ & IIA & - \\
\hline C206 & $\mathbf{C} / \mathbf{G}$ & IIIB & + \\
\hline C485 & $\mathbf{C} / \mathbf{G}$ & IIIB & ++ \\
\hline $\mathrm{C} 80$ & $\mathbf{C} / \mathbf{G}$ & IV & + \\
\hline C123 & $\mathrm{C} / \mathrm{G}$ & IIA & + \\
\hline C414 & $\underline{\mathrm{G} / \mathrm{G}}$ & III & + \\
\hline C918 & $\underline{\mathrm{CC}}$ & III & + \\
\hline C850 & $\mathrm{C} / \mathrm{G}$ & III & - \\
\hline $\mathrm{C} 870$ & $\mathrm{C} / \mathrm{G}$ & IV & ++ \\
\hline C1015 & $\underline{\mathrm{C} / \mathrm{G}}$ & IV & + \\
\hline C998 & $\mathrm{C} / \mathrm{G}$ & IV & ++ \\
\hline C1023 & $\mathrm{CC}$ & - & +++ \\
\hline C1025 & $\underline{\mathrm{C} / \mathrm{G}}$ & III & + \\
\hline C863 & $\mathrm{CC}$ & V & + \\
\hline C837 & $\mathrm{CC}$ & - & +++ \\
\hline C1014 & $\underline{\mathrm{C} / \mathrm{G}}$ & IV & + \\
\hline C1021 & $\mathrm{C} / \mathrm{G}$ & IV & + \\
\hline C1003 & $\mathrm{C} / \mathrm{G}$ & IV & ++ \\
\hline$\underline{\text { C968 }}$ & $\mathrm{C} / \mathrm{G}$ & - & ++ \\
\hline C1032 & $\mathrm{C} / \mathrm{G}$ & - & ++ \\
\hline C989 & $\mathrm{C} / \mathrm{G}$ & - & ++ \\
\hline$\underline{\text { C980 }}$ & $\mathrm{C} / \mathrm{G}$ & IV & + \\
\hline C990 & $\mathrm{C} / \mathrm{G}$ & II & +++ \\
\hline C947 & $\mathrm{C} / \mathrm{G}$ & IV & + \\
\hline C935 & $\underline{\mathrm{C} / \mathrm{G}}$ & IV & + \\
\hline C804 & $\mathrm{CC}$ & & +++ \\
\hline C1019 & $\mathrm{C} / \mathrm{G}$ & III & + \\
\hline C1017 & $\underline{\mathrm{CC}}$ & I & +++ \\
\hline C1002 & $\mathrm{C} / \mathrm{G}$ & III & + \\
\hline C1016 & $\mathrm{CC}$ & II & +++ \\
\hline C866 & $\mathrm{CC}$ & I & +++ \\
\hline
\end{tabular}

aPIGK expression was scored as described under Materials and methods. 
Table II. The primers used to amplify the 10 exons of the human PIGK gene.

\begin{tabular}{cll}
\hline Exon & \multicolumn{1}{c}{ Forward } & \multicolumn{1}{c}{ Reverse } \\
\hline 1 & GGATCAAGCAGAACAATTCTTTA & CATATCTAATGTGAACAGCAAGGT \\
2 & TCAGGTGTGTACATCCCGATT & TTACCTGTCAGGAATACCTAGCCTCT \\
3 & TTTTTCCCTAGTCACATTGTCC & TACCTCGTAACTTCTATAATCCACTTC \\
4 & CCCCCTTAGGTAACTGTGGA & TTCCATTTGCCTTTCTTTTCA \\
5 & ACAAGGGCATGGTGGAAAT & ACCGTCTTTTCTGCCACATT \\
6 & TCATTTTTCTTCAGCTACAATGAG & ACAAATGGGGAAAATGCACA \\
7 & TTTTTCCCCCTTTCCATAGC & CAAATCAAGTGAATACTTACAAGGTCA \\
8 & GCATTTATTATTATATATTT & GAGACTAGTATTCTATTC \\
9 & TTTTCCAGCTATAAGGAAGACCA & AAATGAAATGCAAACCTGGTG \\
$10-P 1{ }^{\mathrm{a}}$ & GCAGAAACCGAAGCTGAAAG & CCAAGTTTGCAGTCCTCCAT \\
P2 & TTGCTGCCTGCCCTATTTAC & TTTCACAGCACATTTCCAAAA \\
P3 & TTTTGACTCCTGTGTTTCTGGA & ACACTGAAGCAATAAGGCCAAT \\
P4 & TAATGATGCCATCCTGCAAA & ATGCTTCTTGTGGGAATCATC \\
P5 & GCCTTTCTCACAGTGTTGTGG & TGGGGGAGGAGAAAAAGAAC \\
P6 & GCGGAGCTATTTAGGGTGGT & AGGAACAACTGCCCTTTGAA \\
P7 & GCTTTTTGCCAGCTCTGAAT & GGGCAACATGGTCAATCTTT \\
\hline
\end{tabular}

${ }^{\mathrm{a}} \mathrm{A}$ total of 7 pairs of primers were used to amply and cover the entire exon 10 of PIGK gene.

were amplified and genotyped in triplicate along with positive and negative control templates. Additionally, all the samples were sequenced unidirectionally, and there was $100 \%$ concordance between sequencing and genotyping data obtained through the TaqMan genotyping assay. All experiments were carried out at JHU.

Immunohistochemistry. To study the expression of PIGK protein, we used FFPE tissue samples collected from 45 samples described in Table I. Several serial sections $(5 \mu \mathrm{m})$ from different regions of the tumors were stained using rabbit anti-human PIGK antibody (Abcam \#38445) for determining protein expression. Staining and evaluation was performed as described earlier $(13,14)$. For comparison, all sections were processed in parallel. All experiments were carried out at JHU.

PIGK constructs and transfection. The wild-type (wt, C/C) human PIGK gene was subcloned into SalI and NotI sites of the phosphorylated cytomegalovirus (pCMV)/myc/ER plasmid (Invitrogen) to express the exogenous protein in the endoplasmic reticulum (ER) as PIGK is localized and functions in the ER (10). The resultant plasmids were resequenced using the ABI BigDye cycle sequencing kit (Applied Biosystems) for verification of the insert sequences. An empty $\mathrm{pCMV} / \mathrm{myc} / \mathrm{ER}$ and a Green Fluorescence Protein (GFP) expressing pCMV/myc/ER-GFP plasmids were also used as controls. In transfections, HepG2 and Hep3B cells were transiently transfected with wt-PIGK plasmid in the presence of the FuGene 6 transfection reagent (Roche Applied Science). An empty $\mathrm{pCMV/myc/ER} \mathrm{vector} \mathrm{was} \mathrm{used}$ for mock transfection. We also used GFP expressing pCMV/ myc/ER plasmid vector as a control. Cells were analyzed $24 \mathrm{~h}$ post transfection. Positive cell clones were confirmed to express
wt-PIGK by immunofluorescence analysis using the fusion protein tag anti-myc-FITC antibody (Invitrogen).

Reverse-transcription PCR. Total RNA was extracted from wt-PIGK transfected and non-transfected Hep3B cells after 24 h using Qiazol reagent following the manufacturer's instruction (Qiagen). Conventional RT-PCR was carried out in $50 \mu \mathrm{l}$ reaction volume as described earlier (14). The primers used for PIGK were forward 5'-CCACTTTGCCTTTCTCTCCA-3'; reverse 5'-GCCCCATTCAGATCCTCTTC-3'.

Statistical analysis. $\chi^{2}$ or Fisher's exact tests were used as appropriate. Student's t-test or non-parametric Wilcoxon rank sum test was also used as appropriate. All p-values are two-sided and all confidence intervals are at the $95 \%$ level. Computations for all the analysis were performed using the Statistical Analysis System (SAS).

\section{Results}

Distribution of SNP 1048575 among the CRC patients. In an earlier study, we observed a low expression of PIGK protein in tumors compared to paired normal tissues of some CRC patients (11). We hypothesized that such low expression could be due to mutation in the coding regions of the PIGK gene. Therefore in this pilot study, we examined all 10 exons of the PIGK gene by direct sequencing in 45 primary CRC tumors. No mutations were detected in the coding regions, however, we discovered a SNP (rs1048575; $\mathrm{C} / \mathrm{C} \rightarrow \mathrm{C} / \mathrm{G}$ or $\mathrm{G} / \mathrm{G}$ ) in the 3'UTR of the PIGK gene in $67 \%$ (30/45) of the CRC patients (Table I and Fig. 1). Schematic representation of the location of the ancestral and altered allele in PIGK is shown in Fig. 2. This observation was 
A
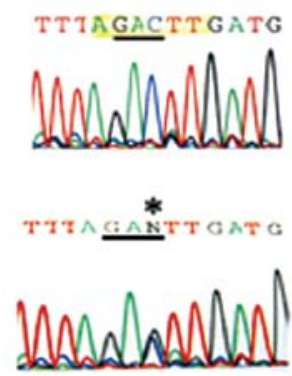

TTTA $\stackrel{*}{\text { TA }}$ TTGATG

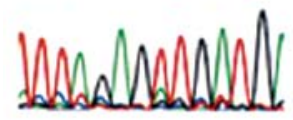

B

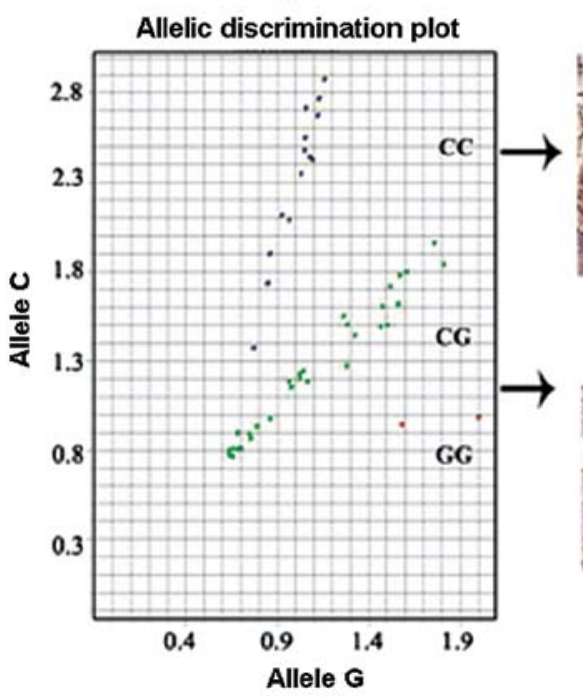

C

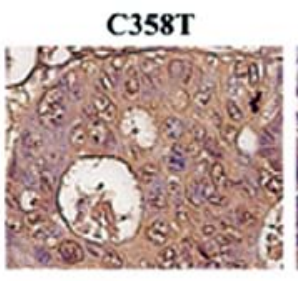

C206T
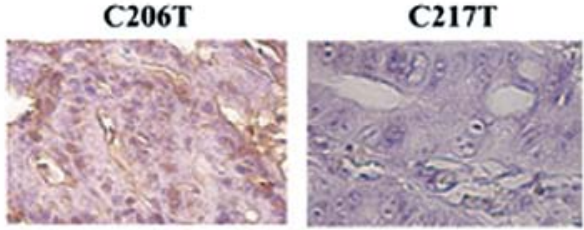

Figure 1. Distribution of the SNP-1048575 allele and PIGK expression in CRC patients. (A) Distribution of the SNP-1048575 allele in the CRC patients determined by DNA sequencing. Presence of altered allele $(\mathrm{C} / \mathrm{G})$ is indicated by an asterisk. (B) Genotyping of the SNP-1048575 allele in CRC patients. The distribution pattern $(\mathrm{C} / \mathrm{C}, \mathrm{C} / \mathrm{G}$ or $\mathrm{G} / \mathrm{G})$ is indicated in the allelic discrimination plot. (C) Significantly low $(\mathrm{P}<0.002)$ expression of corresponding PIGK protein in $\mathrm{CRC}$ patients with altered $(\mathrm{C} / \mathrm{G})$ alleles compared to the patients with the ancestral $(\mathrm{C} / \mathrm{C})$ alleles (indicated by arrows). $\mathrm{T}$, tumor.

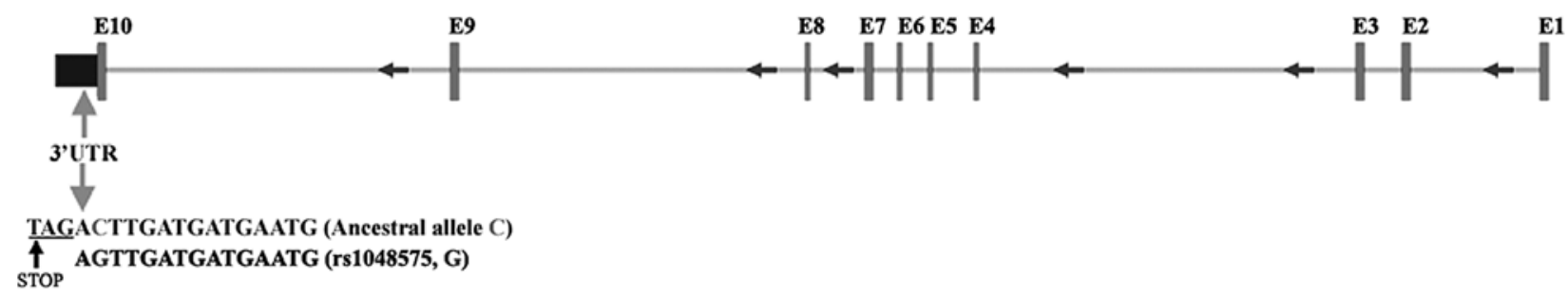

Figure 2. Schematic representation of the location of SNP-1048575 at the 3'UTR of the PIGK gene. The ancestral allele (C) is shown in red whereas the altered allele (G) in blue at the 3'UTR (blue square indicated by an arrow). The SNP-1048575 is located immediately after the stop codon (TAG) as indicated. E, exon.

A

\section{T T AGACTTG}

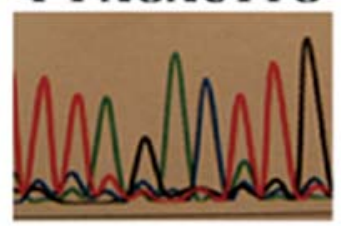

B

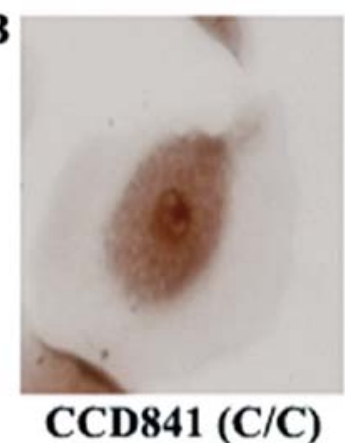

TTAGANTTG
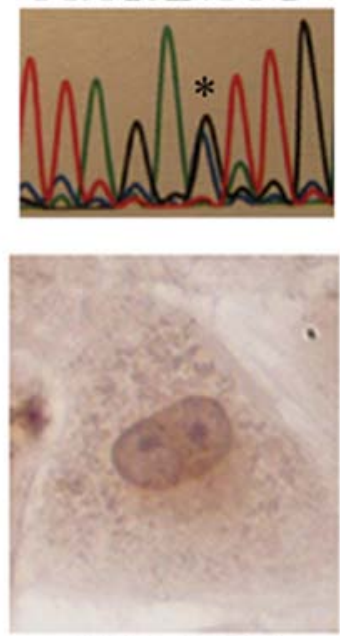

FHC (C/G)
Figure 3. Distribution of SNP-1048575 allele and PIGK expression in transformed colon cell lines. (A) Distribution pattern of SNP-1048575 allele in CCD841 and FHC colon cell lines. Presence of altered allele $(\mathrm{C} / \mathrm{G})$ is indicated by an asterisk. (B) Expression of PIGK protein in FHC cell line with altered allele $(\mathrm{C} / \mathrm{G})$ is significantly low $(\mathrm{P}<0.002)$ compared to the CCD841 cell line with ancestral alleles $(\mathrm{C} / \mathrm{C})$. further confirmed by genotyping the SNP-1048575 in all the above samples (Table I, Fig. 1B). Of the 45 CRC patients, 26 were of Jewish and 17 were of Arabian origin. The ethnicity of the remainder of the 3 patients was unknown. Eighty-five percent $(22 / 26)$ of the Jewish patients showed the altered alleles (C/G or $\mathrm{G} / \mathrm{G})$ whereas $47 \%$ (8/17) of the Arabian patient populations was detected with the altered alleles (Table I, Fig. 1A and B). The number of Jewish patients with the altered alleles was significantly higher (Student's t-test; $\mathrm{p}=0.03$ ) compared to the Arabian patient populations.

Association between SNP-1048575 and PIGK protein expression in CRC patients. To examine whether there was any correlation between the altered alleles $(\mathrm{C} / \mathrm{G}, \mathrm{G} / \mathrm{G})$ and PIGK protein expression in the CRC patients, we performed IHC on FFPE tissue sections from all $45 \mathrm{CRC}$ patients. The expression of PIGK protein was significantly lower $(\mathrm{p}<0.002)$ in all of the patients with altered genotype $(\mathrm{C} / \mathrm{G}$ or $\mathrm{G} / \mathrm{G} ; 30 / 45,67 \%)$ compared to the ancestral genotype (C/C; 15/45, 33\%) (Table I and Fig. 1C).

Association between SNP-1048575 and PIGK protein expression in transformed colon cell lines. We also determined the 


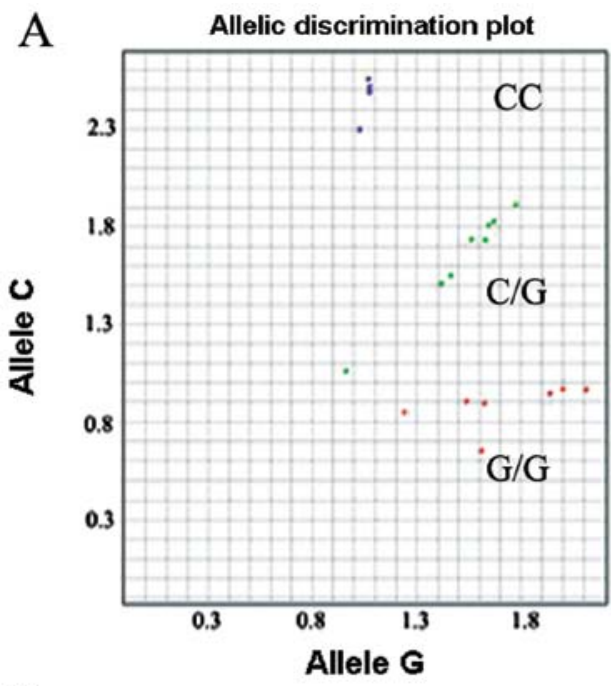

C

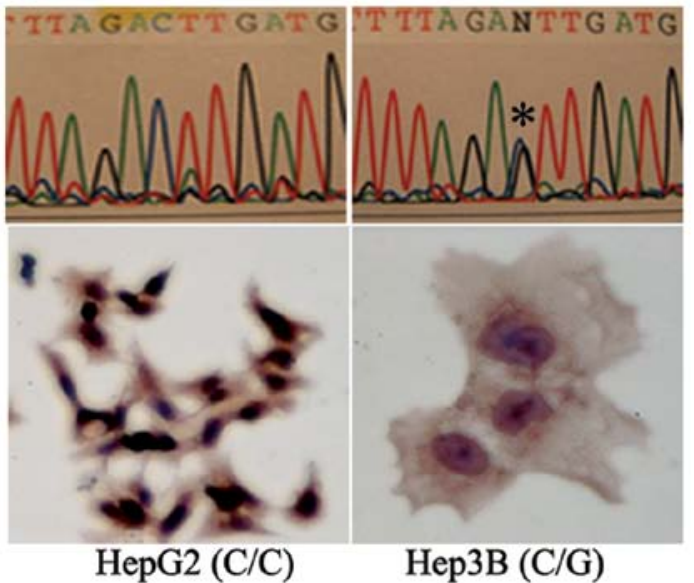

B
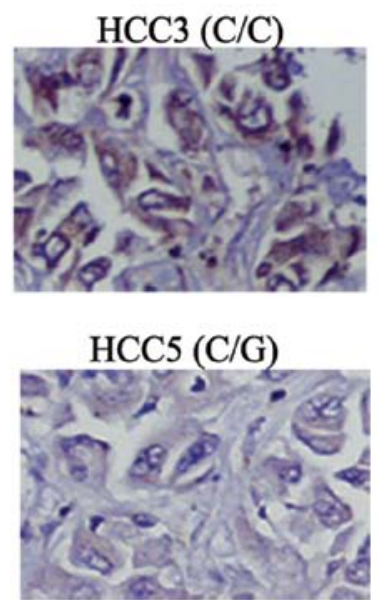

D

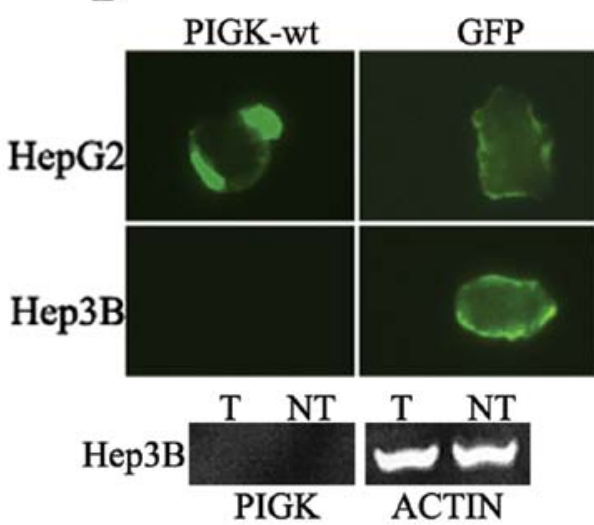

Figure 4. Distribution of SNP-1048575 allele and PIGK expression in HCC patients. (A) Distribution of SNP-1048575 allele in the HCC patients. The distribution pattern $(\mathrm{C} / \mathrm{C}, \mathrm{C} / \mathrm{G}$ or $\mathrm{G} / \mathrm{G})$ is indicated in the allelic discrimination plot. (B) Expression of PIGK protein is significantly low (P<0.002) in $\mathrm{HCC}$ patients with altered (C/G, HCC5) alleles compared to the patients with the ancestral (C/C, HCC3) alleles. (C) Distribution pattern of SNP-1048575 allele in HepG2 and Hep3B liver cancer cell lines (upper panel) determined by DNA sequencing. Presence of altered allele (C/G) is indicated by asterisk. Expression of PIGK protein is significantly low $(\mathrm{P}<0.002)$ in Hep3B line with altered $(\mathrm{C} / \mathrm{G})$ alleles compared to HepG2 cell line with ancestral $(\mathrm{C} / \mathrm{C})$ alleles $($ lower panel). (D) Exogenously expressed wildtype PIGK protein (PIGK-wt) was detectable in the HepG2 cells but not Hep3B cells (upper panel). Control GFP proteins were detectable in both the cell types using the same expression cassette. The PIGK-wt gene was not detected at the mRNA level in Hep3B cells. ACTIN was used as a control. T, transfected; NT, mock transfected.

SNP-1048575 allele distribution and corresponding PIGK expression in a couple of transformed colon cell lines. One colon line (CCD841) exhibited the ancestral alleles $(\mathrm{C} / \mathrm{C})$, whereas the other line (FHC) exhibited the altered alleles $(\mathrm{C} / \mathrm{G})$ (Fig. 3A). Immunohistochemical analysis also revealed a significantly lower (Student's t-test, $\mathrm{p}<0.002$ ) expression of the PIGK protein in the FHC-colon line carrying the altered alleles $(\mathrm{C} / \mathrm{G})$ compared to the CCD-841 cell line with the ancestral alleles (C/C) (Fig. 3B).

Association between SNP-1048575 and PIGK protein expression in HCC patients and cell lines. Similar to the CRC patients, our earlier study also demonstrated a low expression of PIGK in some primary HCC tumors (11). Therefore, we also examined 5 HCC patients and two HCC cell lines (Hep3B and HepG2) for PIGK genotype (SNP-1048575) and corresponding protein expression. We observed altered alleles (C/G or G/G) (Fig. 4A) and corresponding low PIGK protein expression (Fig. 4B) in 4 out of $5(80 \%)$ primary HCC tumors. Among the HCC cell lines, HepG2 line exhibited ancestral C/C alleles, whereas Hep3B showed altered $\mathrm{C} / \mathrm{G}$ alleles (Fig. 4C, upper panel). Similar to the HCC patients, Hep3B line with the altered alleles $(\mathrm{C} / \mathrm{G})$ exhibited significantly low (Student's t-test, $\mathrm{P}<0.002$ ) PIGK protein expression compared to the Hep3B line carrying the ancestral (C/C) alleles (Fig. 4C, lower panel).

Forced overexpression of wild-type PIGK in liver cancer cell lines. To examine the exogenous PIGK protein expression status, we transiently transfected both HepG2 (C/C alleles) and Hep3B (C/G alleles) cell lines with wt-PIGK constructs. As shown in Fig. 4D (upper panel), we could detect exogenously expressed PIGK protein in HepG2 (C/C) cells, but no PIGK expression was detectable in Hep3B $(\mathrm{C} / \mathrm{G})$ cells. The control GFP protein was detectable in both cell lines using the same expression cassette. We also examined the mRNA expression level of the exogenously expressed wt-PIGK in Hep3B $(\mathrm{C} / \mathrm{G})$ 
cells. As shown in Fig. 4D (lower panel), no mRNA expression was detected in Hep3B cells.

\section{Discussion}

The human PIGK gene is involved in the key step of transferring GPI-anchor to the respective protein molecules in the plasma membrane (10). However, its precise role in tumorigenesis remains poorly defined. In an earlier study, we observed a significantly low expression of the PIGK protein in some human CRC, HCC and UCC patients (11). Thus, we hypothesized that somatic mutation in the coding regions of PIGK might be associated with such low expression as shown for other genes in human cancers (15). Therefore, we examined the coding regions of the PIGK gene and corresponding protein expression in $45 \mathrm{CRC}$ patients of both Jewish and Arabic ethnicity where CRC incidences are high, particularly among the Jewish population (2-4). No somatic mutations were detected in the coding regions of PIGK, but we discovered an SNP (rs1048575) located immediately after the stop codon at the $3^{\prime}$ UTR in a majority of the CRC patients with a concomitant decrease in PIGK protein expression. As per the HapMap database (16; http://www.ncbi.nlm.nih.gov), the altered SNP-1048575 was reported in different population with $\mathrm{C}$ allele (wild-type) being more frequent. However, no association of the altered allele $\mathrm{G}$ with any diseases has so far been reported. Our observation in CRC patients correlates well with the results obtained in a several transformed colon cell lines, further suggesting that altered PIGK expression may be an early event in colon carcinogenesis. In a recent study, 3' UTR polymorphisms in the BRCA1 gene were shown to be associated with reduced gene activity and this alteration was proposed as a possible breast and ovarian cancer risk factor (17). Similar to the CRC patients, we observed altered alleles ( $\mathrm{C} / \mathrm{G}$ or $\mathrm{G} / \mathrm{G})$ and corresponding low PIGK protein expression in some HCC patients and cell lines. Moreover, by forced overexpression, wild-type PIGK protein was detectable in the HCC cell line HepG2 with the ancestral $(\mathrm{C} / \mathrm{C})$ alleles but not in Hep3B carrying the altered alleles $(\mathrm{C} / \mathrm{G})$. This could be a consequence of transcriptional deregulation of the PIGK gene as we could not detect the exogenously expressed PIGK mRNA. Another possible mechanism could be regulation of PIGK by potential micro-RNAs through perfect or imperfect complementarity mechanism(s) at the sites located within the $3^{\prime}$ UTR of this gene $(18,19)$.

In summary, our results demonstrate for the first time a link between deregulated expression of PIGK and SNP-1048575 in CRC patients and also suggest a possible association between altered PIGK expression and CRC susceptibility.

\section{Acknowledgements}

The study was supported by a grant from Flight Attendant Medical Research Institute and Elsa U. Pardee Foundation to B. Trink; US-Egypt Joint Science and Technology fund (58-3148-169), A.D. Williams (646299) and Elsa U. Pardee Foundation (548424) to S. Dasgupta. PBF holds the Thelma Newmeyer Corman Chair in Cancer Research in the VCU Massey Cancer Center.

\section{References}

1. Markowitz SD and Bertagnoli MM: Molecular basis of colorectal cancer. N Engl J Med 361: 2449-2460, 2010.

2. Barchana M, Liphshitz I and Rozen P: Trends in colorectal cancer incidence and mortality in the Israeli Jewish ethnic populations. Fam Cancer 3: 207-214, 2004.

3. Rozen P, Rosner G, Liphshitz I and Barchana M: The changing incidence and sites of colorectal cancer in the Israeli Arab population and their clinical implications. Int J Cancer 120: 147-151, 2007.

4. Rozen P, Liphshitz I and Barchana M: Changing sites of colorectal cancer in the Israeli Jewish ethnic populations and its clinical implications. Eur J Cancer Prev 16: 1-9, 2007.

5. Poynter JN, Figueiredo JC, Conti DV, et al: Colon CFR: Variants on 9p24 and 8q24 are associated with risk of colorectal cancer: results from the Colon Cancer Family Registry. Cancer Res 67: 11128-11132, 2007.

6. Pittman AM, Webb E, Carvajal-Carmona L, et al: Refinement of the basis and impact of common 11q23.1 variation to the risk of developing colorectal cancer. Hum Mol Genet 17: 3720-3727, 2008.

7. Tomlinson IP, Webb E, Carvajal-Carmona L, et al: A genomewide association study identifies colorectal cancer susceptibility loci on chromosomes 10p14 and 8q23.3. Nat Genet 40: 623-630, 2008.

8. Tenesa A, Farrington SM, Prendergast JG, et al: Genome-wide association scan identifies a colorectal cancer susceptibility locus on 11q23 and replicates risk loci at 8q24 and 18q21. Nat Genet 40: 631-637, 2008.

9. Cheah PY: Recent advances in colorectal cancer genetics and diagnostics. Crit Rev Oncol Hematol 69: 45-55, 2009.

10. Zacks MA and Garg N: Recent developments in the molecular, biochemical and functional characterization of GPI8 and the GPI-anchoring mechanism. Mol Membr Biol 23: 209-225, 2006.

11. Nagpal JK, Dasgupta S, Jadallah S, Chae YK, Ratovitski EA, Toubaji A, Netto GJ, Nissan A, Sidransky D and Trink B: Profiling the expression pattern of GPI transamidase complex subunits in human cancer. Mod Pathol 8: 979-991, 2008.

12. Dasgupta S, Mukherjee N, Roy S, Roy A, Sengupta A, Roychowdhury S and Panda CK: Mapping of the candidate tumor suppressor genes' loci on human chromosome 3 in head and neck squamous cell carcinoma of an Indian patient population. Oral Oncol 38: 6-15, 2002.

13. Dasgupta S, Bhattacharya-Chatterjee M, O'Malley BW Jr and Chatterjee SK: Reversal of immune suppression in an orthotopic murine model of head and neck squamous cell carcinoma following vaccination with recombinant vaccinia virus expressing IL-2. Cancer Ther 2: 375-388, 2004.

14. Dasgupta S, Bhattacharya-Chatterjee M, O'Malley BW Jr and Chatterjee SK: Inhibition of NK cell activity through TGF-1 by down regulation of NKG2D in a murine model of head and neck cancer. J Immunol 175: 5541-5550, 2005.

15. Ali MA and Sjoblom T: Molecular pathways in tumor progression: from discovery to functional understanding. Mol Biosyst 5: 902-908, 2009.

16. http://www.ncbi.nlm.nih.gov.

17. Pongsavee M, Yamkamon V, Dakeng S, O-charoenrat P, Smith DR, Saunders GF and Patmasiriwat P: The BRCA1 3'-UTR: $5711+421 \mathrm{~T} / \mathrm{T} \_5711+1286 \mathrm{~T} / \mathrm{T}$ genotype is a possible breast and ovarian cancer risk factor. Genet Test Mol Biomarkers 13: 307-317, 2009.

18. Olena AF and Patton JG: Genomic organization of microRNAs. J Cell Physiol 222: 540-545, 2010.

19. Iorio MV and Croce CM: MicroRNAs in cancer: small molecules with a huge impact. J Clin Oncol 27: 5848-5856, 2009. 